ÁREA DE SUBMISSÃO: CONTROLE DE QUALIDADE E INDÚSTRIA FARMACÊUTICA CQIF13

\title{
AVALIAÇÃO DA VIABILIDADE DE COMPRIMIDOS CONTENDO ELEVADO TEOR DE EXTRATOS SECOS DE SCHINUS TEREBINTHIFOLIUS RADDI (AROEIRA-DA- PRAIA)
}

\author{
J. C. B. MACHADO ${ }^{1}$, C. L. S. VIGO ${ }^{2}$, M. R. A. FERREIRA ${ }^{1,2}$, R. DANIELS ${ }^{3}$ e L. A. L. SOARES ${ }^{1}$
}

${ }^{1}$ Universidade Federal de Pernambuco, Centro de Ciências da Saúde, Departamento de Ciências Farmacêuticas

${ }^{2}$ Universidade Federal de Pernambuco, Centro de Biociências, Programa de Pós-graduação em Inovação Terapêutica

${ }^{3}$ University of Tübingen, Department of Pharmaceutical Technology, Alemanha

E-mail para contato: Janaina_carla29@hotmail.com

RESUMO - Schinus terebinthifolius Raddi, "aroeira-da-praia", é uma das espécies amplamente utilizadas no arsenal terapêutico popular, empregada no tratamento de inflamações e feridas. Entretanto, os estudos sobre o desenvolvimento tecnológico ainda são escassos. Deste modo, o objetivo do trabalho foi avaliar a viabilidade de comprimidos contendo elevado teor de extratos secos por aspersão de S. terebinthifolius. Assim, comprimidos foram preparados a partir de formulações contendo proporções do extrato seco na faixa de 40 a $60 \%(\mathrm{~m} / \mathrm{m})$. Os comprimidos foram avaliados quanto dureza e variabilidade de massa. As curvas de força de compressão vs dureza obtidas na faixa de 3 a $9 \mathrm{kN}$, evidenciaram a transferência das propriedades reológicas e compressionais dos extratos aos respectivos comprimidos. Portanto, os dados demonstram a necessidade do incremento das propriedades reológicas do extrato seco para obtenção de comprimidos viáveis para produção industrial.

Palavras-chave: Schinus terebinthifolius. Comprimidos. Fitoterápicos.

ABSTRACT - Schinus terebinthifolius Raddi, "aroeira-da-praia", is one of the species widely used in the popular therapeutic arsenal, applied to the treatment of inflammations and wounds. However, the studies on technological development are still rarely. Therefore, the objective of this study was to evaluate the feasibility of tablets containing high content of spray dried extracts from S. terebinthifolius. Thus, tablets were prepared from formulations containing different proportions of the dry extract, ranged from 40 to $60 \%(w / w)$. The tablets were evaluated for hardness and mass variability. The compression force curves vs. hardness obtained in the range of 3 to $9 \mathrm{kN}$ showed the transfer of the rheological and compression properties of the extracts to the respective tablets. Therefore, the data showed the need to increase the rheological properties of the dry extract to obtain viable tablets for industrial production. 


\section{INTRODUÇÃO}

O uso das plantas medicinais através da tradição popular, principalmente em países em desenvolvimento, desperta interesse em indústrias farmacêuticas e alimentícias, pela busca de novos agentes terapêuticos e nutracêuticos, impulsionando as pesquisas sobre o tema. Schinus terebinthifolius Raddi (Anacardiaceae), conhecida como "aroeira da praia" ou "aroeira vermelha", representa uma das espécies consolidadas pelo uso popular no Brasil, onde podem ser encontradas em regiões de mata atlântica até o cerrado (TORRES, 1981). Utilizada na medicina popular para inflamações uterinas e cura de feridas e úlceras. Na literatura estão descritas para a espécie atividade antiinflamatória, antimicrobiana, antifúngica e atividade cicatrizante de feridas e ulceras (MARTINEZ et al., 1996; ALVES et al., 2012; DOS SANTOS et al., 2012). Entretanto, um ponto importante a ser observado são os inúmeros trabalhos sobre atividade biológica e segurança de S. terebinthifolius (CARLINE et al., 2010; LEITE et al., 2011), porém, poucos trabalhos sobre o desenvolvimento tecnológico de produtos à base de plantas.

As formas farmacêuticas sólidas agregam vantagens quando comparadas as formas líquidas, no que se refere à estabilidade química, física e microbiológica, facilidade de manuseio e transporte, além de fornecer uniformidade de dose. Para tanto, esforços tecnológicos são empregados na obtenção de formas sólidas, devido à complexidade da matriz vegetal, assim novos processos de produção são requeridos, capazes de atenderem aos parâmetros de qualidade e serem reprodutíveis (SOARES et al., 2005; CORTÉS-ROJAS, et al., 2015). Por outro lado, a utilização de extratos secos por aspersão torna-se difícil devido as características reológicas e de compressibilidade desses pós, apresentam-se finos, higroscópicos e com pouca capacidade de compressão e fluidez (GALLO et al., 2015). Desta forma, o desenvolvimento de novos processos e formulações para produção de formas sólidas, a partir de extratos secos vegetais por aspersão com características adequadas para o processo de compressão direta é um importante desafio para a indústria de fitoterápicos. Portanto, o objetivo deste trabalho foi avaliar a viabilidade de comprimidos contendo elevado teor do extrato seco de S. terebinthifolius.

\section{MATERIAIS E MÉTODOS}

Para condução dos experimentos foi utilizado extrato seco de S. terebinthifolius (ESASt), obtido por aspersão em Spray-Drier MSD 1.0 (LabPlant) a partir de extratos hidroalcoólicos fornecidos pela empresa Hebron (Caruaru-PE). Dióxido de silício coloidal (Aerosil) foi empregado como adjuvante de secagem na proporção de $10 \%(\mathrm{~m} / \mathrm{m})$ em relação ao teor de sólidos do extrato. $\mathrm{O}$ extrato seco, a celulose microcristalina e a carboximetilcelulose sódica (AcDi-Sol) foram misturados em misturador tipo Turbula modelo T2C (Willy A. Bachofen, Suíça) por 10 minutos. Em seguida foram adicionados à mistura o dióxido de silício coloidal (Aerosil 200) e o estearato de magnésio e misturados por mais 5 minutos.

Os comprimidos foram preparados em máquina de comprimir alternativa Korsch (mod. EK 0), empregando como ferramentas de compressão punções com superfície plana e lisa, de diametro de $10 \mathrm{~mm}$. O punção superior foi instrumentado com quatro fitas de alongamento modelo 3/120 LY 11 (HBM, Alemanha) para medida da força de 
compressão. Como ponte de freqüência foi empregado amplificador HBM (Alemanha) tipo K52 com dispositivo KWD 523D (HBM, Alemanha). Os dados foram apropriados em computador com auxílio do programa Messefix ${ }^{\circledR}$ v. 2.3 (Dr. R. Herzog, Tübingen, Alemanha).

Tabela 1 - Composição ponderal das formulações de comprimidos.

\begin{tabular}{l|c}
\hline Ingredientes & Proporção $(\%, \mathrm{~m} / \mathrm{m})$ \\
\hline Extrato seco de S. terebinthifolius & 40,$0 ; 50,0$ ou 60,0 \\
Estearato de magnésio & 2,0 \\
Aerosil & 1,0 \\
Ac-Di-Sol & 5,0 \\
Celulose Microcristalina & 52,$0 ; 42,0$ ou 32,0 \\
\hline
\end{tabular}

A resistência radial dos comprimidos foi determinada em durômetro Erweka modelo TBH-30 $(n=6)$. A massa dos comprimidos foi estabelecida em balança de precisão imediatamente após a fabricação $(n=5)$.

\section{RESULTADOS E DISCUSSÃO}

Os resultados obtidos para comprimidos do extrato seco de $S$. terebinthifolius caracterizados quanto à variabilidade de massa e dureza, estão apresentados na figura 1.

Figura 1 - Curvas de força de compressão (dureza e variabilidade de massa). Influência da proporção de extrato seco sobre as propriedades dos comprimidos.
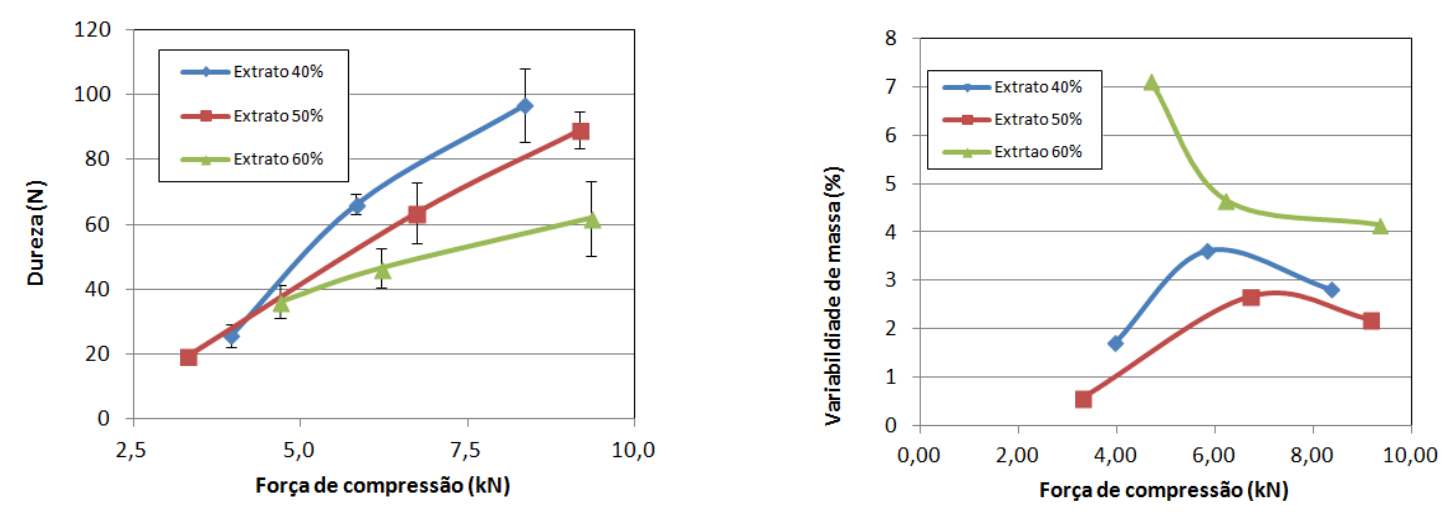

O aumento da proporção de extrato nas formulações teve efeito deletério sobre a resistência dos comprimidos. Ademais, aumento na variabilidade dos pesos médios dos comprimidos foi observada. Estes resultados denotam a necessidade de aprofundamento da investigação tanto do comportamento de deformação, quanto da compressibilidade dos sistemas particulados obtidos. De modo que a compressão direta de sistemas desta natureza só será possível quando apresentarem fluidez e compressibilidade, desafio conhecido para a fabricação de formas sólidas a partir de plantas. (SOARES et al., 2005). Gallo e colaboradores (2015) observaram influência da constituição química 
sobre características físicas dos compactos como porosidade, densidade e tempo de desintegração, ao utilizar extratos secos por aspersão de diferentes espécies vegetais.

A força empregada no processo de compressão é um dos parâmetros físicos mais importantes na produção de comprimidos (ANGIOLUCCI et al., 2012), como observado na figura 1 o aumento da força incrementa a dureza em todas as concentrações dos extratos, porém quanto a variabilidade de massa, o aumento da força de compressão resulta em menor variedade de massa nos comprimidos para todas as formulações testadas. Este efeito pode ser observado quando a força exercida ultrapassa o limite de elasticidade, passando de um sistema elástico para não plástico, quando a pressão é retirada a deformação não é revertida, formando sistemas mais compactos (ANGIOLUCCI et al., 2012). Entretanto, mais estudos sobre o processo de produção e qualidade dos produtos obtidos são necessários para atender as exigências dos órgãos regulamentadores.

\section{CONCLUSÃO}

As formulações permitiram a produção de comprimidos contendo elevado teor do extrato seco de S. terebinthifolius. Entretanto, em proporção superior a $50 \%$ de extrato, os sistemas não apresentaram redução na dureza dos compactos e incremento na variabilidade do peso médio em razão da baixa compressibilidade e fluidez do ativo. Novos estudos e estratégias de desenvolvimento (formulação e/ou outros passos tecnológicos) serão conduzidos para assegurar sistemas particulados com as propriedades desejáveis de fluxo e compressibilidade.

\section{REFERÊNCIAS}

ALVES, L.A. et al. In vitro activity of Schinus terebinthifolius(Brazilian pepper tree) on Candida tropicalis growth and cell wall formation. Acta Odontol Latinoam., v. 25(3), p.287-92, 2012.

ANGIOLUCCI, T. et al. Estudo de propriedades físico-químicas envolvidas no processo de compactação de uma formulação experimental contendo zidovudina. Rev Ciênc Farm Básica Apl., v. 33(2), p. 233-243, 2012.

CARLINI, E. A. et al. Assessment of the Toxicity of the Brazilian Pepper Trees Schinus terebinthifolius Raddi (Aroeira-da-praia) and Myracrodruon urundeuva Allemão (Aroeira-do-sertão). Phytother. Res., v. 27(5), p.692-8. 2013

CORTES-ROJAS, D.F. et al.Optimization of spray drying conditions for production of BidenspilosaL. dried extract. Chem. Eng. Res. Des., v. 93, p. 366-376, 2015

DOS SANTOS, O.J. et al. Schinus terebinthifolius Raddi (Anacardiaceae) in the healing process of gastrorraphy in rats. Arq. Bras. Cir. Dig., v. 25, n. 3, p.140-6, 2012.

FB 5. Farmacopeia Brasileira. 5 ed., Brasília: ANVISA, 2010.

GALLO, L.; RAMÍREZ-RIGO, M. V.; PIÑA, J.;BUCALÁ, V. A comparative study of spray-dried medicinal plant aqueous extracts. Drying performance and product quality. Chem. Eng. Res. Des. v.104, p.681-694, 2015.LEITE, S.R., et al..Randomized clinical trial comparing the efficacy of the vaginal use of metronidazole with a Brazilian pepper tree (Schinus) extract for the treatment of bacterial vaginosis. Braz. J. Med. Biol. Res., v. 44, n.3 , p.245-52, 2011.

MARTINEZ, M.J., et al. Atividade antimicrobiana Schinus terebinthifoliusRaddi (copal). Rev Cub Plantas Med., v. 1, n. 3, p. 37-39. 1996.

SOARES, L.A.L. et al. Dry granulation and compression of spray-dried plant extracts. AAPS PharmSciTech., v. 6(3), Article 45, p. 359-366 2005.

TORRES, D. M. Catálogo de plantas medicinais (y alimenticias y utiles) usados em Paraguay. Asunción, 1981.

\section{AGRADECIMENTOS}

Os integrantes agradecem a FACEPE (APQ-0493- 4.03/14), CNPq (308386/2015-9), CAPES e DAAD. 